\title{
SUSTAINING CORPORATE PERFORMANCE THROUGH EMPLOYEE WELL-BEING: APPLYING THE STINSON WELLNESS MODEL IN A BUSINESS ENVIRONMENT
}

Mark A. Lee, Trinity Western University, Langley, British Columbia, Canada

David D. Stinson, Trinity Western University, Langley, British Columbia, Canada

dx.doi.org/10.18374/IJSM-13-3.7

\begin{abstract}
Sustaining performance in a corporate setting has become an increasingly difficult paradox for leaders of organizations. On the one hand investors and analysts are demanding steady rates of returns on their investments, yet on the other hand the organizational leaders are attempting to navigate a perilous economic environment, typified by uncertainty about what tomorrow will bring and striving to predict from a strategic perspective what will happen over the next three to five years and beyond. In addition, these leaders are also trying to balance the needs of a diverse population of employees, knowing that motivated and creative employees are critical for the success of the organization. At the same time, these employees are equally stressed about what the future holds for them and their careers, given the uncertainty within the organization and the variety of scenarios that might impact them, such as threats of layoffs and downsizing, plus an ever increasing work load for the survivors of these corporate purges. As a result, the modern work environment has become the antithesis of a bastion of sustainable performance and employee well-being.Within this context, the purpose of this paper is to introduce a new model of employee wellness, which could lead to a better understanding of the contributing factors to employee well-being. The Stinson Wellness Model (Stinson, 2013) will be introduced as a methodology for addressing employee well-being, then in turn the model will be applied within an organizational setting as an intriguing alternative for leaders to use in organizational decision-making, when striving for sustainable corporate performance.
\end{abstract}

Keywords: Sustainable corporate performance; employee performance; organizational well-being; employee well-being; wellness; decision-making; alignment; human resources; strategic decision making. 